\title{
Diffusion of complementary evolving pharmaceutical innovations: The case of Abacavir and its pharmacogenetic companion diagnostic in Italy
} DOI:

10.1016/j.techfore.2018.06.014

\section{Document Version}

Accepted author manuscript

Link to publication record in Manchester Research Explorer

Citation for published version (APA):

Gagliardi, D., Ramlogan, R., Navarra, P., \& Dello Russo, C. (2018). Diffusion of complementary evolving pharmaceutical innovations: The case of Abacavir and its pharmacogenetic companion diagnostic in Italy. Technological Forecasting and Social Change, 134. https://doi.org/10.1016/j.techfore.2018.06.014

Published in:

Technological Forecasting and Social Change

\section{Citing this paper}

Please note that where the full-text provided on Manchester Research Explorer is the Author Accepted Manuscript or Proof version this may differ from the final Published version. If citing, it is advised that you check and use the publisher's definitive version.

\section{General rights}

Copyright and moral rights for the publications made accessible in the Research Explorer are retained by the authors and/or other copyright owners and it is a condition of accessing publications that users recognise and abide by the legal requirements associated with these rights.

\section{Takedown policy}

If you believe that this document breaches copyright please refer to the University of Manchester's Takedown Procedures [http://man.ac.uk/04Y6Bo] or contact uml.scholarlycommunications@manchester.ac.uk providing relevant details, so we can investigate your claim.

\section{OPEN ACCESS}




\title{
Diffusion of complementary evolving pharmaceutical innovations: The case of Abacavir and its pharmacogenetic companion diagnostic in Italy
}

\author{
Dimitri Gagliardi ${ }^{1 *}$, Ronnie Ramlogan ${ }^{1}$, Pierluigi Navarra ${ }^{2}$ and Cinzia Dello Russo ${ }^{2}$ \\ ${ }^{1}$ Manchester Institute of Innovation Research, The University of Manchester, Manchester, UK M13 9PL \\ ${ }^{2}$ Institute of Pharmacology, Catholic University Medical School, L.go F Vito 1 - 00168 Rome - Italy
}

*Correspondence to be addressed to: dimitri.gagliardi@manchester.ac.uk

\section{Pre-print. Please cite as:}

Gagliardi, D., Ramlogan, R., Navarra P., \& Dello Russo, C., (2018) Diffusion of complementary evolving pharmaceutical innovations: The case of Abacavir and its pharmacogenetic companion diagnostic in Italy, Technolgical Forecasting and Social Change, (in press) https://doi-org.manchester.idm.oclc.org/10.1016/j.techfore.2018.06.014

\begin{abstract}
Innovation is increasingly important in the delivery of efficient healthcare; however, the pathways through which medical innovation reach clinical practice are fraught with uncertainty. Further scientific investigation and technological development are normal in medical innovation even when drugs, diagnostics or medical procedures are already adopted. Diffusion studies rarely admit such possibilities as a fundamental element of their conceptual frameworks. This paper explores the diffusion process of an antiretroviral drug (Abacavir) and the introduction of its companion pharmacogenetic test into clinical practice in Italy. This is a landmark case of translational medicine where the principles of pharmacogenetics made an important - applied - contribution to medical innovation shifting the focus away from the diffusion of a complete technology (the drug) towards that of a dynamic technology (Abacavir + developing companion diagnostics). We adopt the historical method to analyse the sequence of events. Key findings show that the diffusion process of a dynamic technology does not fit in the widely accepted S-shaped model for a complete technology. The diffusion phase presents complex interactions amongst the stakeholders involved, each operating on the basis of their own competences within the environment and the regulatory system; the analysis of the diffusion process should proceed through the correct identification of the dynamic technology - the therapy - and cannot be de-coupled from scientific discovery and technological development.
\end{abstract}

Keywords: Medical innovation; Diffusion of innovation; Dynamic technologies; Pharmacogenetic Test; HLA-B*57:01; Abacavir 


\section{Introduction}

Innovation is becoming increasingly important in the delivery of efficient healthcare; however, the pathways through which medical innovation is embedded in clinical practice are fraught with uncertainty and littered with failure. Even when innovation appears to be initially successful, its wide diffusion sometimes results in unforeseen outcomes that may not match the innovators or indeed, the wider societal expectations. This aspect is rarely tackled in the literature dealing with diffusion of innovation.

Ever since the classical work on innovation diffusion of Rogers (1962) the theme of diffusion has attracted the attention of scholars in many domains. Coleman et al (1957) was one of the first studies to develop a framework analysing the diffusion of a new medicine. Here the concern was on understanding the social processes leading to the wider adoption of tetracycline across four American cities by general practitioners. The study found that diffusion followed a contagion-like trajectory wherein professional and personal networks of medical practitioners were important drivers of the widening use of the drug.

Since these pioneering works, innovation diffusion studies grew in scope extending towards forecasting of diffusion paths (Bass, 1969; Bass et al, 2001) and in terms of sophistication (Cho et. al 2012 Semitiel-Garcia \& Noguera-Mendez, 2012), increasingly uncovering important aspects in the process of diffusion of innovation. More recent studies, in fact, have uncovered inextricable links between technological diffusion and socio-economic characteristics (Ilonen et al, 2006); the dynamic saturation limits of the diffusion process in technologies with substitution effect (Michalakelis et al, 2010); the impact of information dynamics on diffusion trajectories (Yucel \& van Daalen, 2011) and the impact of market segmentation and population heterogeneity on technology diffusion (Ferreira \& lee 2014; Guseo \& Guidolin, 2015).

A common feature of these studies is that the diffusion trajectory follows the classical sigmoid shape. Moreover, the vast literature on the diffusion of innovation usually focuses on well-defined technologies either considered through vintage updates or battling for market with substitutes. Increasingly, we may see however, that more and more evolving technologies are hitting the market (Homer, 1987). These are technologies that do have clear market applications but are embedded in complex systems where exogenous and endogenous factors drive or hinder diffusion. As a result of these influences, the diffusion trajectory may not be S-shaped. Moreover, many technologies embedded in these systemic arrangements may not be fully formed though fulfilling their purposes (Greer, 1988). In these cases, further scientific investigation and technological development are necessary. This is normal procedure in medical innovation even when drugs, diagnostics or medical procedures have been introduced in clinic. Yet, mainstream innovation diffusion studies rarely admit such possibilities as a fundamental element of their conceptual frameworks ${ }^{1}$.

This paper aims at exploring the diffusion pattern of one such case. We look at the diffusion of the antiretroviral drug Abacavir (marketed as Ziagen ${ }^{\circledR}$ ), and its companion pharmacogenetic test. It is a well-documented landmark case in HIV/AIDS where the historical reconstruction highlights a 'point of entry' of pharmacogenetics into mainstream pharmaceuticals (Martin and Kroez, 2013). We use it to unravel some of the complexities associated with the diffusion process of the drug and the test as

\footnotetext{
${ }^{1}$ One exception may be the study of Barbera-Tomas and Consoli (2012) where the authors look at uncertainty and technological hybridisation (i.e. the embodiment of multiple competing operational principles within a technology) in the diffusion of innovative technologies in medical implantable devices.
} 
complementary therapeutic devices. The diffusion process in this case is even more interesting in that it involves many domains of competences and, within each domain, scientific discovery and technological development is ongoing as the case unfolds. The deliberate approach targets the integration of pharmaceuticals core-activities either in pharmaceutical science and/or research and development with the science-base outside the pharmaceutical industry in order to benefit from advances in pharmacology, diagnostics and clinical procedural.

The paper is organised as follows. In the next section we provide a review of medical innovation literature in particular of the diffusion of medical innovations. Our interpretative framework is sharpened in the light of relevant theoretical contributions. In section 2 we profile the methodology used. In section 3 we develop the case study. In the last section we provide a discussion of the elements that contributed to the implementation of the pharmacogenetic test and its successful diffusion over the Italian territory, highlighting some indications of future research.

\section{Theoretical background}

Innovation in medicine is a complex process. However in the medical innovation literature, the innovation process has been reduced to a sequence of tightly defined and discrete activities (Figure 1). Diffusion of innovation in clinical practice occurs at the last stage of the innovation process which begins after the science had been resolved, clinical research had demonstrated the effectiveness and efficacy (including cost efficacy) and regulatory approval gained.

Figure 1. - The bench to bed process is described in the figure below:

From the Bench

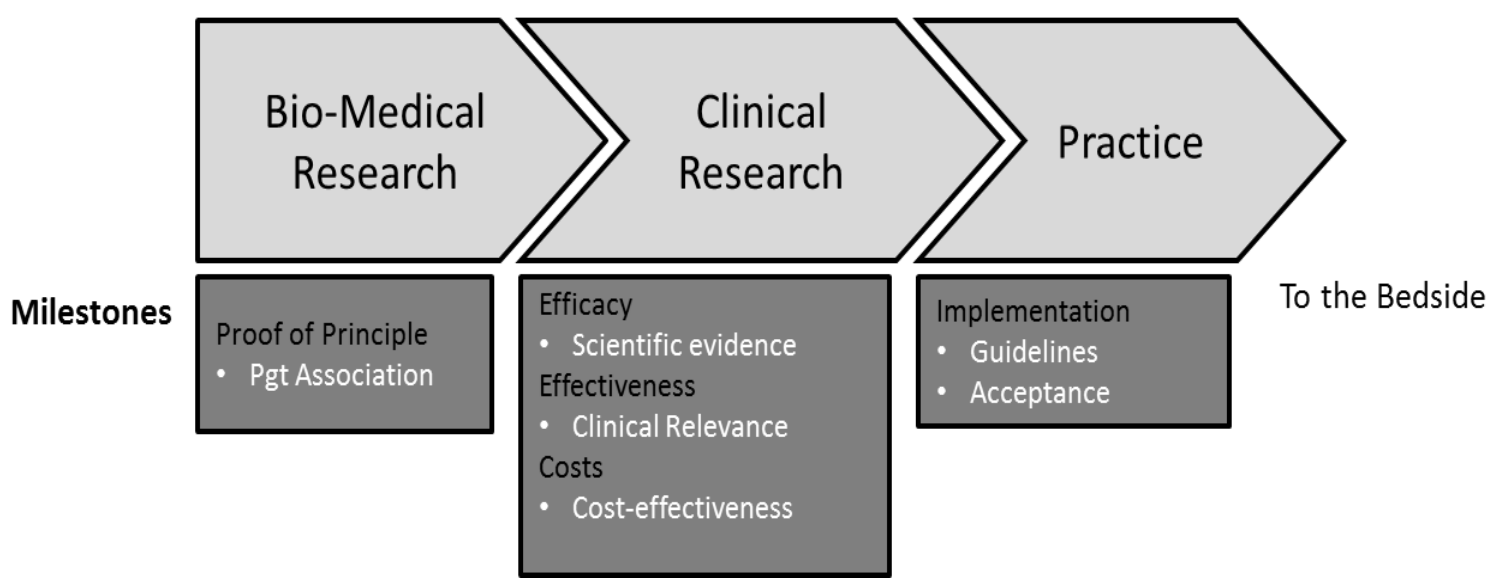

Source: adapted from Swen et al, (2007). Pgt, = pharmacogenetic.

Whilst in the classical diffusion tradition various factors affecting the adoption of an innovation ${ }^{2}$ relate to distinctive phases of diffusion (from early/lead adopters to mass markets), in the medical domain McKinlay (1981) identifies several stages that are partly different from those described in the mainstream literature (Pullen et al, 2012). Differences are primarily due to issues related to the stringent regulation and the knowledge/skill intensity necessary for the adoption and integration of medical innovation in the medical profession and to institutionalised routines (to be discussed later). However, McKinlay (1981) identifies the starting point of a successful diffusion trajectory in the

\footnotetext{
${ }^{2}$ These may be summarised by the followings factors exerting a positive effect on diffusion: 1) relative advantage over existing technologies, 2) fit with users' values, 3) availability to trials and 4) result of the adoption of innovation may be easily observable. Complexity, on the other hand, is seen as factor hindering diffusion.
} 
publication of 'promising reports' i.e. studies or demonstrations highlighting that a technology or a practice may provide a relative advantage with respect to existing technologies or practices. Diffusion of medical innovation then gain momentum through 'professional and organisational adoption'; in this phase, the scattered support of the innovation in the first phase gains commitments within the profession and some institutional support. The third stage consists of 'public acceptance and state/payer endorsement'. At this stage, the innovation gains recognition from the wider stakeholder base and early users and organisations are legitimatised for their early adoption. The innovation is then formally accepted and eventually reimbursed by the state or thirdparty payers (i.e. insurance). Finally, a medical innovation is integrated into standard procedures (routines); observational reports are then conducted on what has been adopted as "the most appropriate way of proceeding with a particular problem or situation" (p. 387). The author points out that not all stages in the envisaged sequence need to be successfully dealt with in order to confirm the success of a medical innovation in clinical practice. Confirmation would come from randomised clinical trials.

Greenhalgh et al, (2004) differentiate between two alternative diffusion modes: i) diffusion as a process through which new or improved knowledge may spread within a system in an unplanned, informal, decentralised and horizontal manner - mediated by peers and ii) active dissemination whereby the diffusion of innovation is planned, formal and often centralised - likely to occur through hierarchical structures. They posit that between the two modes there exists a continuum where elements of the first mode, diffusion in the sense of Rogers (1995) may overlap with those of the second, planned dissemination. In a later paper, Greenhalgh et al (2005) report that in evidencebased medicine the provision of implementation guidelines assumes a central role in the diffusion process. In particular, the process of diffusion is seen as the final stage of a substantially linear progression not unlike the process described by Swen et al (2007) and operationalised once the 'funnel model' still used by the pharmaceutical industry has successfully run its course (Paul et al. 2010, p 2006; Calcoen et al. 2015, p. 162).

Within the rationalist science tradition, supporters argue that the translation of scientific evidence into clinical practice is relatively unproblematic (Dawson, 1995). If problems were to occur, they would be due to knowledge or behavioural gaps somewhere along the linear sequence (Haines and Jones, 1994). Consistently, numerous publications focused on providing solutions or alternative pathways to plug the gaps so that sound and context-neutral research could reach clinical practice and change clinical behaviour.

However, this model has been challenged by many authors. Grol (2001), for example, argues that evidence-based diffusion strategies may be unsuccessful given that guidelines, based on a restricted view of the research conducted in any specialist field, may translate in ambiguous practices. Guidelines, tainted by the fragmentation of knowledge deriving from collating specialist research work from various fields, often result too generalist i) for single/unique patients presenting individual health problems ${ }^{3}$; ii) usually disruptive of the routine of the learned and tested clinical

\footnotetext{
${ }^{3}$ On a more fundamental matter: personalisation of medicine and the promise of genomics for individually formulated therapies, Tutton (2012) observes that a shift towards a vision of patient as an individual as opposed as the 'average patient' in current medicine may embody a fundamental change in perspective from the universalist approach to a more experimental setting that considers technological advances as well as environmental and societal aspects associated to illness.
} 
practices and organisations and iii) generally, are not cost-neutral. Within this context, Ferlie et al (2001) argued that evidence-based practices in diffusion should be incremental and adaptive since they are based on a complex evolution of medical knowledge which needs to be explored in its multifaceted domains, understood and internalised by the scientists as well as by the clinicians and contextualised before it can be operationalised. According to Greenhalgh et al (2005) the implementation of clinical guidelines should be complemented by information and education campaigns to inform clinicians and influence the opinion leaders to generate a race to excellence, and provide behavioural incentives to the front-end clinicians to adjust their routines accordingly. The complexity of the diffusion of medical innovation derives from multiple and unpredictable interactions characteristic of (i) the particular setting within which the diffusion process occurs and (ii) the actors and their agency operating within such contexts (Grol, 2007; Talke \& Hultink, 2010).

Such studies and others that followed similar lines of enquiry (Skinner and Staiger, 2005; Burke et al, 2007; Liu and Gupta, 2012) analyse the diffusion of innovation through the characteristic S-shaped curve considering the factors fuelling the dynamics or as a stage-gate process linking the diffusion of innovations to the 'satisfaction' of certain criteria and/or as the overcoming of objective hurdles.

What will be the consequences for diffusion if there were endogenous forces at play within the system whilst a new technology was spreading? Such a question switches the spotlight onto many cases of 'anomalous' innovation diffusion that are all too frequent in the medical domain. Perhaps the most frequent of these concerns the co-evolution of medical technologies and the diffusion of dynamic technologies and techniques whilst undergoing changes following emerging research findings and ongoing clinical developments.

The first aspect, co-diffusion of technologies, was tackled originally by Rogers (1995) in introducing the concept of diffusion of a technology cluster. A technology cluster is a group of two or more technologies where the diffusion of one is dependent on the diffusion of complementary technologies which either increase the value of the original technology or extend its market. Mclntyre et al. (1988) added to Rogers' notion of cluster dynamics in their discussion of supporting technologies. These are products or services, developed independently by different actors, that capitalise on the diffusion of a given technology. Co-diffusion was explored by Buckling and Sengupta (1993) in their analysis of the dynamics of co-diffusion of scanners and barcodes. Having identified a focal innovation and a potentially complementary independent technology, Buckling and Sengupta (1993) argue that strategic interactions in the market may favour a successful pairing of the technologies thereby reinforcing complementarities and creating co-dependence (see Figure 2 adapted for our case study). The end result will be a process of enhanced co-diffusion in which the focal innovation is set on a diffusion trajectory sustained by the complementary technology (p.152).

Figure 2. Co-Diffusion conceptual framework 


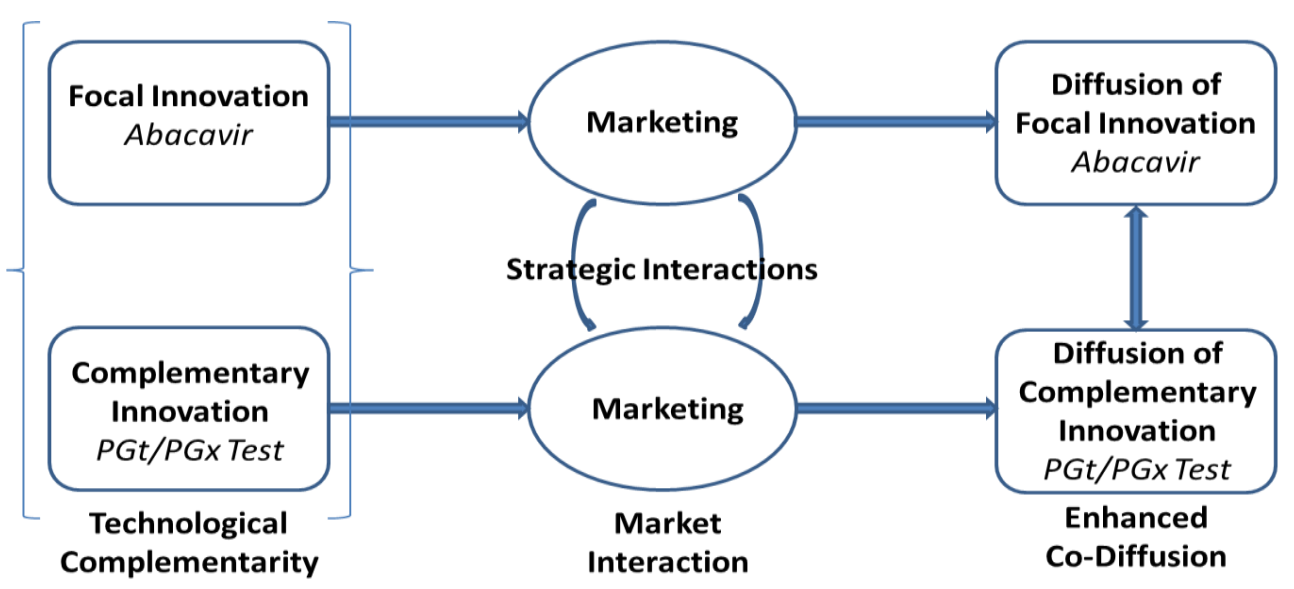

Source: adaptation of the conceptual framework of Buckling and Sengupta (1993, p.150).

A second aspect highlighted above concerns the diffusion patterns of technologies that are not complete either in terms of practical use (i.e. fully responding to the clinical needs) or because, even though functional, they are embedded into a fast evolving technological domain. Amongst the early studies attempting to resolve this issue, Homer (1987) developed a multi-loop diffusion model to analyse the complex dynamics of evolving technologies. He envisaged the diffusion of a medical technology as part of a complex process of evaluation, trials, competence building and ongoing performance evaluation. The process is affected by factors endogenous to clinical practice such as the extent to which the technology is already in use and the support such as marketing and postsales training and evaluation deriving from formal and informal assessments. Exogenous factors are also important. These include attributes of the technology, the social systems in which it diffuses, pricing and purchasing decision centres and standards of performance which are integral to clinical practice and connected with the functioning of healthcare institutions. The outcome of Homer's model is that, as happens with many medical technologies, diffusion trajectories might not be Sshaped as posited by classical diffusion theory. Greer (1988) comes to a similar conclusion by distinguishing between the dissemination and use of a final product or technology (formed/complete technology) and the diffusion of products or technologies that are in the process of being developed yet already used in clinic (dynamic technology). While the former, though more studied, is an exception in medical innovation, evolving/dynamic medical technologies are the norm. Their diffusion trajectories are characterised by structural uncertainty which is a fundamental problem of discovery and development associated with medical innovation.

The study of diffusion of medical practices over the last decades has uncovered an increasing number of dimensions of the innovation process from scientific research to diffusion. What happens when scientific and technological problems linger whilst new challenges are emerging in the course of diffusion? How does this process sit with the presence of multiple agencies?

Mina et al (2007) argue that the processes involved in medical innovations are rarely reconcilable with a model based on input-output/outcome but are 'better seen as trajectories of improvement sequences' (p791). Here, refinements are cumulative and progressive and involve the co-evolution of scientific and technological knowledge within social networks. Thus progress in the area of medical innovation is contingent on continuous feedback between science, technology and practice and as we shall see, these three domains are not discrete entities but may be actively engaged at any stage of the process. The discussion complements Mokyr's (1998) who suggests that progress in medical knowledge and technology is, by nature, oriented even if it is, at times, discontinuous. 
There is, in fact, a link between existing knowledge and further advances since new investigations are grounded on the body of accumulated knowledge and the direction of said investigations generally follow a given logic (Mokyr, 1998, p.132). Within this process, novel techniques are added to the set of available options some of which might be adopted and used, others might prove to be useful in the future, whilst some may never be selected.

The understanding provided by this strand of literature elucidates on the systemic instituted process of medical innovation from knowledge generation and variation across the relevant scientific and technological domains and the institutional settings within which these processes evolve. However, it also presents insights into the diffusion tail of the innovation process, especially the diffusion of innovations in clinical practices. Serious inroads have been made by discussing the relation between demand, needs and regulations in the diffusion process. Thus the delivery of healthcare involves the close intertwining of the service and manufacturing economy (Metcalfe et al, 2005). Best et al (2012) argues that this is about a large system transformation (LST) where the system is characterised by complex adaptive dynamics. This involves a number of heterogeneous stakeholders facing complexities within their own fields and interfacing with complementary disciplines, acting according their own agency (Jerome-D’Emilia \& Begun, 2005; McKilay \& Marceau, 2012; Blume, 2013; Shen \& Shih, 2016).

The theory highlights two important levels of complexity. One related to the diffusion process of dynamic technologies and the other linking the diffusion process to discovery and on-going technological development. In the remainder of this paper, we show that the diffusion of a medical innovation is a complex and messy process that does not map neatly into the funnel model as a discrete and final stage.

\section{Methodology}

The present study is directed at looking deeper into the sequence of events that brought the wider application of the pharmacogenetic test into clinical practice. It is conducted through secondary desk-based research, analysis of documents, collation of privileged information and a series of interviews in order to trace back the milestones, the motivations, the strategy and the practices promoted by the patent holders in pursuing the 'rescue' of Abacavir and preparing the 'market' for its successor(s). Therefore, the objective of the study is that of looking into a sequence of events from a retrospective/historical perspective (Flick, 2014). The reconstruction of a sequence of events from documents and correspondence may limit our understanding of the reasons behind the decisions that were made and on the tacit knowledge shared by the protagonists of our story (Bowen, 2009 and Flick, 2014). Therefore, we proceeded to the collection of primary qualitative information through interviewing directly the network managers, the principal investigators of the research units and the representative of the patient advocacy organisation (Harvey, 2011). This strategy was deemed appropriate in order to understand 'why' certain decisions were undertaken and 'how' the network was formed and operated (Yin, 2013).

In detail, we have explored the network of Italian research centres sponsored by ViiV Healthcare, the current patent holder of the Abacavir. We focused on the competences brought in to support a strategy to keep the compound viable assuring patients' safety and the motivation of the participants to join the network and shaping ViiV Healthcare's strategy for the diffusion of the 
pharmacogenetic test. Whilst the domain of the study is clearly global in nature and reach, we adopt an Italian-centric view since the clinical genetic unit of ViiV Healthcare Ltd. is based in Verona, Italy. The company interacted extensively with other Italian organisations, research units and researchers for matters related to the pharmacogenetic test for the identification of patients carrying the Human Leucocyte Antigen - B*57:01 (HLA-B*57:01) variant.

A series of interviews with several stakeholders involved in Italian HLA-B*57:01 Network were conducted between April and August 2015 after a pilot conducted amongst the authors. The network participants were individually contacted by email, and once they replied agreeing to participate, the interview protocols were forwarded. Subsequent structured phone interviews, lasting from 30 minutes to 1 hour, were recorded with the consent of the interviewed for further analysis.

Interviews conducted with the coordinators including the two managers of the Italian HLA-B*57:01 Network (one manager for clinical virology ${ }^{4}$ and one for the clinical practice) focused on two types of questions: 1) their involvement in the organisation of the network and 2) their direct involvement in the research activities including collaboration with other network partners, ViiV Healthcare and research partners external to the network.

Thirteen interviews were conducted with the principal investigators and co-investigators representing virology/pharmacology laboratories and infectious diseases (or equivalent) clinics. The subject of the interviews was their competences, their interests in participating in the network, the collaboration patterns within the network, with the network's sponsor and with centres or clinics outside the networks. Finally we asked about the outcomes of their activities. Each interview ended with an open question concerning issues that the respondent considered relevant for the study.

Finally, an unstructured interview was carried out with the deputy president of an organisation most active in Italy as advocacy group for HIV/AIDS patients and involved, at the ministerial level, in the design and implementation of the clinical guidelines as well as in the network activities.

We have explored their competences (personal and of their research groups), their interests and the research outcomes through $\mathrm{CV}$ analysis.

All interviews focused on the period of the network formation and activities. The timeline used included enquiries on the state of play of the network's activities and how it evolved from 2012 when it began operating. Follow-up interviews were made during the elaboration of the case study to gain further clarity on some aspects, explore issues emerging, obtain updates on the activities carried out within the network (i.e. new scientific and technical advances, conference contributions, publications, reactions to new regulations/guidelines, new drugs launch etc.) and discuss emerging challenges in the areas where the Italian HLA-B*57:01 Network operates.

This method assures that the historical reconstruction is consistent throughout the investigation (Golden, 1992; Miller et al. 1997).

\section{Case study}

\footnotetext{
${ }^{4}$ Clinical virology laboratories provide diagnostic services for the detection and monitoring of HIV infection, including viral load and serology, HIV genotyping and antiviral resistance testing, and often lymphocyte counts. These clinical units are therefore important actors in the management of HIV infectious disease, promoting diagnostic development and providing relevant services.
} 
Abacavir was approved for human use in 1998 in the US and in 1999 in Europe. However its diffusion was slowed by the regulatory authorities due to the possible occurrence of a hypersensitivity reaction (HSR) in HIV infected patients. To support the diffusion of the drug, the patent holder at the time $(\mathrm{GSK})^{5}$ devised a cautionary strategy to control HSR detrimental effects. This consisted of training practitioners in the early diagnosis/identification of the HSR symptoms followed by the immediate and permanent discontinuation of any therapeutic regimen containing Abacavir. Subsequently, it was discovered that the HSR was associated with a particular genetic trait of patients, the presence of Human Leucocyte Antigen - B*57:01 (HLA-B*57:01) allele (Mallal et al, 2002 and 2008; Heterington et al, 2002). This meant that the drug could only be effectively prescribed if a further layer of testing was introduced to rule out the risk of hypersensitivity. This new form of testing originated in the field of pharmacogenetics. Rather fortuitously, GSK in 2002 had invested in a venture to learn from emerging pharmacogenetic techniques and methodologies related to their commitment in the Human Genome Project. This knowledge later became strategic for applying discoveries in this field to soften the decline of the drug and smooth over the introduction of newer antiretroviral regimens containing Abacavir. However, it was not until 2008 that the first clinical applications of the test started to emerge. Between the second half of 2008 and 2009 the Food and Drug Administration of the US and the European Medicine Agency changed the drug label - introducing a box warning - stating a mandatory test to genotype HIV infected patients. This recommendation further disadvantaged the clinical use of Abacavir relative to competing products such as Tenofovir by Gilead the market leader for this class of drugs since 2002. The strategic priority of ViiV Healthcare Ltd thus became how to implement the test to identify patients carrying the HLA-B*57:01 allele. For the strategy to be effective, hence redeeming the poor market performance of Abacavir, the test would have to be integrated within the initial testing procedures of potential HIV infected patients.

In effect, the box warning created the incentive for the development of fast and reliable methods to identify HLA-B*57:01 carriers. In the context of the present case GSK first and later ViiV Healthcare sought to capitalise on their scientific, technological and innovation-driven approaches to diagnostic technologies and the pharmacogenetic-specific competences that had been invested in. This was happening within a system lacking standardised regulatory guidelines. Within a few years, research and development activities yielded several proprietary tests developed by major players in the diagnostic market and non-patented Laboratory Developed Tests (LDT) with rapid turnaround time and at affordable costs (Stocchi et al, 2012) ${ }^{6}$.

\footnotetext{
${ }^{5}$ From 2009 onward the patent holder of Abacavir (Ziagen ${ }^{\oplus}$ ) and all the combination medicinal products containing Abacavir is ViiV Healthcare Ltd. a specialty joint venture focusing on HIV/AIDS formed by GSK, Pfizer and from 2012, Shionogi, who brought a new drug, Dolutegravir, to the partnership (https://www.viivhealthcare.com/media/press-releases/2012/october/shionogi-and-viiv-healthcareannounce-new-agreement-to-commercialise-and-develop-integrase-inhibitor-portfolio.aspx).

${ }^{6}$ Diagnostic testing is usually performed in virology and pharmacology laboratories either through proprietary commercial kits or via own developed techniques. The commercial tests can be classified as in vitro diagnostic devices, thus are developed and marketed according specific regulations (Van Norman, 2016). Tests developed within a specific laboratory can be classified as laboratory developed tests (LDTs), i.e. 'designed, manufactured and used within a single laboratory' (Draft Guidance for Industry, Food and Drug Administration Staff, and Clinical Laboratories: Framework for Regulatory Oversight of Laboratory Developed Tests (LDTs) http://www.fda.gov/downloads/MedicalDevices/DeviceRegulationandGuidance/GuidanceDocuments/UCM41 6685.pdf. These tests, whose detailed methodologies and validation data are published in peer-reviewed
} 
This case captures the final stage of a process spanning almost 20 years that, at this point, should have involved the diffusion of a sound practice consisting of a focal innovation (Abacavir and Abacavir-containing drugs ${ }^{7}$ ) and the complementary pharmacogenetic test.

After the first inroads made following the implementation and validation of a real time quantitative (Q)-PCR test in 2009-2010 (Dello Russo et al, 2011), proprietary commercial tests including those based on this technique became progressively available ${ }^{8}$. Such one-time testing was considered a cost-effective allocation of healthcare resources after an initial period of uncertainty and evaluation (Wolf et al, 2010; Kauf et al, 2010; Alagoz et al, 2016). Moreover, early characterisation of patients was seen as strategic in the reduction of HSR; testing began to be implemented in clinics.

To capitalise on the progress in diagnostic techniques ViiV Healthcare promoted a network of several Italian virology laboratories with shared interest in the test and with complementary capabilities, the aim being to ensure high quality standards of genotyping in clinical practice. The Italian HLA-B*57:01 Network began its operations in early 2013.

Interviews and documental evidence suggested that the central objectives of ViiV Healthcare were to facilitate access to the test and its diffusion for those HIV infected patients who were not previously tested and to introduce the test during the initial diagnostic phase in drug-naïve patients. The purpose of this was to effectively routinize it within the assessments normally carried out at the diagnosis of HIV infection (i.e. HIV viral load, CD4 lymphocyte count, and viral genotyping) by clinical virology laboratories rather than in specialised pharmacogenetic/immune-genetic laboratories. Thus, all these evaluations, including the pharmacogenetic screening for the HLA-B*57:01, would be done on the same specimen and by the same diagnostic laboratory. This practice should also be independent from whether the patient is prescribed an Abacavir-containing therapy or not and the genotype should be included in the patient's clinical record for future reference. This is a relevant issue considering that HIV infected patients may require changes of therapy during the currently extended clinical course of the disease.

In order to link the diffusion of Abacavir and Abacavir-containing drugs to the test effectively (i.e. exploit the strategic interaction between the focal innovation and the complementary emerging technology), it was necessary to:

1) Standardise screening practises especially those based on Q-PCR, both from commercial kits and LDTs, since, technically, these would 'fit' with the other tests routinely carried out at the diagnosis of HIV infection.

2) Optimise screening quality by evaluating/validating existing LDTs and commercial kits.

3) Generate further data and relative analyses of HSR in screened patients given that this is still a grey area greatly under researched.

international biomedical journals, are patent free. Currently, LTDs are regarded as crucial determinants for a rapid implementation of personalized medicine, despite an ongoing discussion on matters as patients' safety, promotion of innovation and regulatory oversight (FDA, 2017).

${ }^{7}$ While patent protection for Abacavir has recently expired, the drug remains an essential component of several fixed-dose formulations, including Trizivir $^{\circledR}$ (Abacavir/Lamivudine/Zidovudine, FDA and EMA approval in 2000), Epzicom/Kivexa ${ }^{\circledR}$ (Abacavir/Lamivudine, FDA and EMA approval in 2004) and the recently approved Triumeq $^{\circledR}$ (Abacavir/Lamivudine/Dolutegravir, launched in Italy at the beginning of 2016) under patent protection.

${ }^{8}$ Duplic $\alpha$ by EuroClone; HLA B*5701 Real-TM by Sacace; COBAS ${ }^{\circledR}$ AmpliPrep/COBAS ${ }^{\circledR}$ TaqMan $^{\circledR}$ HLA-B*5701 by Roche; HLA B*5701 Real Time by Nuclear Laser Medicine. 
4) Diffuse further the practice of screening - to non-typified patients and naïve patients through information and dissemination of the knowledge inherent to the test, demonstration of its clinical relevance in terms of costing and of its therapeutic value.

However, not unlike the problem sequence that characterises medical innovation (Metcalfe et al. 2005; Consoli and Ramlogan, 2008), we observe various hurdles that needed to be overcome as well as new unanticipated issues emerging, as it were, moving the goalposts. These provided the reasons and the motivations for ViiV Healthcare to initiate and progress with the promotion of the Italian HLA-B*57:01 Network and, to a greater extent matched the expectations and the scientific interests of the participants even though the motivations of the latter were clearly different.

The strategic market interactions highlighted by Buckling and Sengupta (1993) turned into the setting of an innovative organisational structure. From the company's perspective, this consisted in the continuation of improvement of the drug-based therapy by studying new combination drugs of which Abacavir is a component. Whilst from the perspective of consolidating complementarity with the dynamic technology (the pharmacogenetic test), the research effort needed to be extended to the wider stakeholder base in their effort to advance the technology through ongoing or new research both at the bench and in the clinic.

The Italian HLA-B*57:01 Network

At the date of the first round of interviews, the network consisted of 12 research laboratories based mainly in universities and university hospitals and 13 clinical facilities located within university hospitals, in private and public hospitals.

Members of the network are distributed across the Italian peninsula, with a broad national coverage, as depicted in Figure 1.

Figure 3: The Italian HLA-B*57:01 Network 


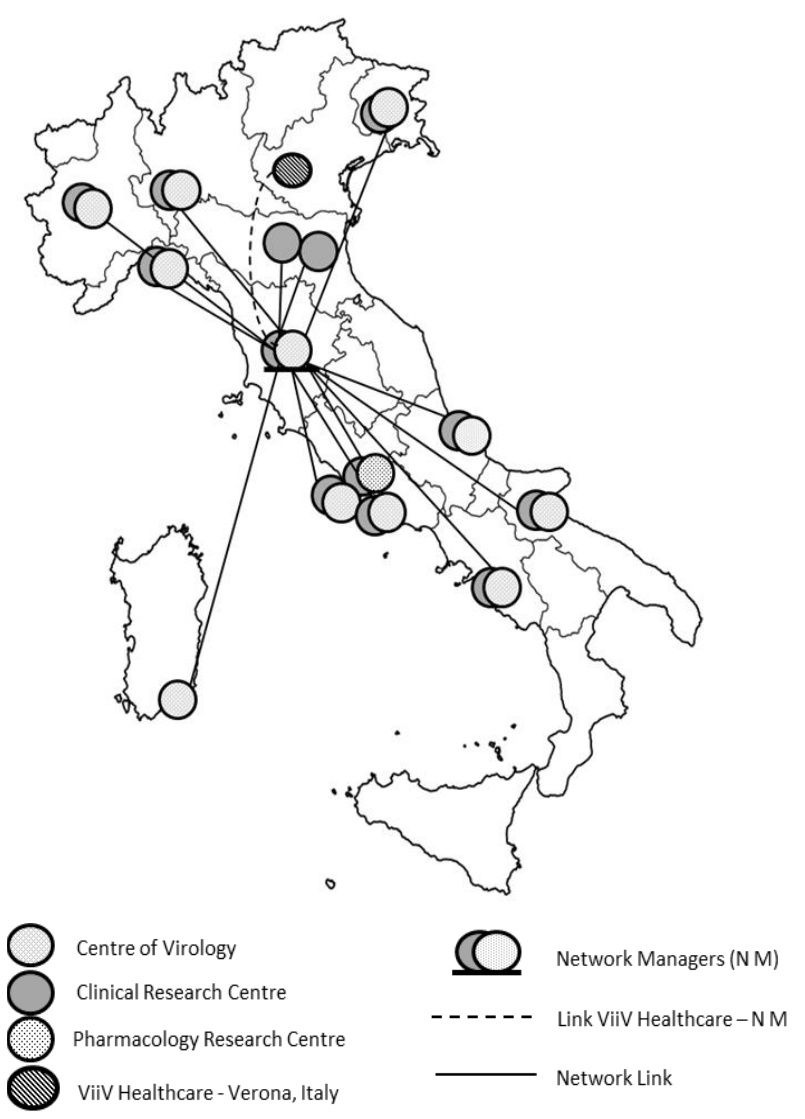

Source: own elaboration

In line with the scope of the undertaking, the Italian network grouped scientists and clinicians with a variety of complementary skills covering both the domains where the tests are developed, validated and performed - mostly virology laboratories - and where these are prescribed to patients and evaluated - clinical centres performing research. The network also includes an important patients' advocacy organisation key members of which are involved at a very high level in the definition of the clinical guidelines, research design and evaluation in Italy and internationally (Table 1).

Table 1. Description of the Italian HLA-B*57:01 Network and characteristics of the participants

\begin{tabular}{|c|c|c|c|c|c|c|}
\hline \multirow[b]{2}{*}{ Functions } & \multicolumn{3}{|c|}{ Scientific and testing laboratories } & \multicolumn{3}{|c|}{ Clinical and clinical research centres } \\
\hline & Org. Type & $\begin{array}{l}\text { Primary } \\
\text { Competences } \\
\text { of the } \mathrm{PI} / \text { co-I }\end{array}$ & $\begin{array}{l}\text { Secondary } \\
\text { Competences of the } \\
\text { research groups }\end{array}$ & Org. Type & $\begin{array}{l}\text { Primary } \\
\text { Competences } \\
\text { of the } \mathrm{PI} / \mathrm{co}-\mathrm{I}\end{array}$ & $\begin{array}{l}\text { Secondary Competences } \\
\text { of the research/clinical } \\
\text { groups }\end{array}$ \\
\hline $\begin{array}{l}\text { Network } \\
\text { Management }\end{array}$ & $\begin{array}{l}\text { University of } \\
\text { Siena }\end{array}$ & Biologist & $\begin{array}{l}\text { Microbiology and } \\
\text { Virology }\end{array}$ & $\begin{array}{l}\text { University of } \\
\text { Siena } \\
\text { Clinical } \\
\text { Hospital }\end{array}$ & Medical Doctor & Infectious Diseases \\
\hline \multirow[t]{8}{*}{$\begin{array}{l}\text { Network } \\
\text { Participants }\end{array}$} & 11 Labs & $\begin{array}{l}6 \text { Medical } \\
\text { Doctors }\end{array}$ & $\begin{array}{l}\text { Microbiology and } \\
\text { Virology }\end{array}$ & $\begin{array}{l}12 \text { Clinical } \\
\text { Centres }\end{array}$ & $\begin{array}{l}12 \text { Medical } \\
\text { Doctors }\end{array}$ & Infectious Diseases \\
\hline & & 10 Biologists & Infectious Diseases & & & Tropical medicine \\
\hline & & & & & & Viral Immunology \\
\hline & & & $\begin{array}{l}\text { Pharmacology and } \\
\text { Toxicology }\end{array}$ & & & $\begin{array}{l}\text { Medical Mycology and } \\
\text { bacteriology }\end{array}$ \\
\hline & & & Pharmacogenomics & & & \\
\hline & & & Immunology and & & & Endocrinology \\
\hline & & & Allergic pathologies & & & Haematology \\
\hline & & & $\begin{array}{l}\text { Epidemiology and } \\
\text { Public Health }\end{array}$ & & & Oncology \\
\hline
\end{tabular}




\begin{tabular}{|c|c|c|c|c|c|c|}
\hline \multirow[b]{2}{*}{ Functions } & \multicolumn{3}{|c|}{ Scientific and testing laboratories } & \multicolumn{3}{|c|}{ Clinical and clinical research centres } \\
\hline & Org. Type & $\begin{array}{l}\text { Primary } \\
\text { Competences } \\
\text { of the PI/co-I }\end{array}$ & $\begin{array}{l}\text { Secondary } \\
\text { Competences of the } \\
\text { research groups }\end{array}$ & Org. Type & $\begin{array}{l}\text { Primary } \\
\text { Competences } \\
\text { of the } \mathrm{PI} / \text { co-I }\end{array}$ & $\begin{array}{l}\text { Secondary Competences } \\
\text { of the research/clinical } \\
\text { groups }\end{array}$ \\
\hline & & & Clinical Pathology & & & $\begin{array}{l}\text { Nephrology } \\
\text { Paediatrics }\end{array}$ \\
\hline \multirow[t]{2}{*}{$\begin{array}{l}\text { Patients } \\
\text { advocacy }\end{array}$} & $\begin{array}{l}\text { Non- } \\
\text { governmental } \\
\text { organization } \\
\text { (NGO) - } \\
\text { advisory and } \\
\text { advocacy }\end{array}$ & Physics & \multicolumn{4}{|c|}{$\begin{array}{l}\text { Editorial coordination, authorship and membership to the executive board of the } \\
\text { Italian "Guidelines for the use of antiretroviral drugs and the clinical-diagnostic } \\
\text { management of HIV - } 1 \text { infected patients" }\end{array}$} \\
\hline & & & \multicolumn{4}{|c|}{$\begin{array}{l}\text { Authorship/co-authorship of numerous scientific papers on HIV/AIDS, preventative } \\
\text { measures, research design and therapy evaluation }\end{array}$} \\
\hline
\end{tabular}

Source: own elaboration on primary documentation and members' CVs

Diagnostic companies are not involved with the network. This happened by design since ViiV Healthcare Ltd. and the network wanted to focus on diagnostics developed within the Italian clinical setting thus avoiding formal or informal endorsement of proprietary tests developed elsewhere.

\section{Setting up: management and operations}

The network, mostly self-organised around themes set out together with ViiV Healthcare, is led by two-tier coordination groups, one for the virology undertakings and the other relating to clinical research dealing directly with HIV infected patients in clinics and hospitals. Both network coordinators are based at the University of Siena and Siena University Hospital.

They were entrusted with coordination tasks given their expertise in microbiology and virology, and infectious diseases respectively. Both centres are research active with a substantial track record of publications in HIV/AIDS as well as other virology areas. Moreover, both centres were veterans in collaborating with ViiV Healthcare in matters related to HIV/AIDS, including their participation in a previous network ${ }^{9}$.

During the planning phase of the Italian HLA-B*57:01 Network both teams in Siena were involved with ViiV Healthcare in the recruitment of other members. By late 2012, it was decided that conditions for joining the network should be rather fluid and open to virology centres or clinics that i) had already implemented the HLA-B*57:01 test in Q-PCR, ii) where in the process of implementing it and iii) had planned to tool-up shortly thereafter. This decision was linked with the planning of a broad range of activities including training, competence building, sharing of research and clinical protocols as well as internal assurance procedures.

The last two aspects, sharing of research and clinical protocols and internal assurance procedures, relate directly with the prospective activities of the network and constituted the driver for the effective exchange of experiences within and between the two groups - virologists and clinicians -.

\footnotetext{
${ }^{9}$ The Network managers were involved in the evaluation in clinical practice of the genotypic HIV-1 tropism test used in place of a more complex phenotypic assay that, at the time, was available only as remote service in specialized laboratories. This experience, now terminated constituted, in the view of the respondent, a very positive experience that developed from 4 founding centres to some 15 collaborating research units, brought to extensive scientific and clinical publications (Svicher $V$ et al., 2011), and importantly the implementation in routine clinical practices of the genotypic tropism test (Svicher V et al., 2010).
} 
Sharing research and protocols and setting assurance procedures instituted the knowledge-base of the network, in the words of the leading virologist: "the reference hub for all members".

The participation of virology research centres in the activities of the network was mainly inspired by the organisation of scientific activities and issues of practicality. From the organisational perspective the motivation of the research centres was both to extend their collaborative effort to tap into complementary capabilities in neighbouring fields and demonstrate their willingness to explore new research avenues, including the clinical aspects of the phenomenon. From a practical perspective, this opportunity was associated with access to data and audit given that the presence of the allele in the general population is rather low, $4-5 \%$ in Italy ${ }^{10}$. Local access to a restricted number of samples would not enable detailed scientific studies.

These factors have led to high levels of commitment by the network members especially because the case presented many open research questions whilst new research challenges were still emerging.

One of the pharmacology centres, based in Rome, joined the network for "historical reasons", meaning that researchers in this department had already been involved in the development of a pharmacogenetic test in Q-PCR and worked in collaboration with ViiV Healthcare on this topic. Their interest in the network activity is linked to the opportunity to advance on their previous scientific endeavour in a more open collaboration setting.

The clinicians highlighted the importance of providing the patients with the best available treatment in any given condition. The implementation of the test is an essential decision tool in the physicians' prescribing practice. A better understanding of how it works, assurance of the quality of the results and close collaboration with the virology are paramount in accomplishing the clinical needs of the physicians and their patients. Of no less importance is also the fact that these activities are geared towards a better understanding of 1 ) the HSR either linked to the HLA-B*57:01 or other factors and 2) further methodologically and practically advances on the ways to tailor the therapy based on the characteristics of the patients: "after all, Abacavir is one of the few molecules that works closely with genetics and there is still a lot to understand" (as reported by the head of the infectious diseases clinic operating in Rome $)^{11}$. The implications of these observations are clearly relating to practical aspects deriving from the needs of clinicians in their day-to-day activities and their research activities and clinical trials in relation to the production of new knowledge in areas related to the pathology that are still uncertain in diagnostic and therapeutic fields.

In addition, clinicians mentioned the importance of learning in this field since other drugs with a companion diagnostic test are becoming available and the competences learnt within this setting are potentially transferable to other adjacent areas of their specialisation.

\section{The organisation of activities: ensuing achievements}

The members of the Italian network are all involved in the HLA-B*57:01 screening of HIV infected patients. Amongst the scientific activities promoted within the network ViiV Healthcare's interests

\footnotetext{
${ }^{10}$ The Allele Frequency Net Database (http://www.allelefrequencies.net/)

${ }^{11}$ It is also the case of pointing out that an important aspect of the clinical study foreseen at the inception of the study has been put on hold and is under re-assessment. In particular retrospective studies on the HSR have come to a halt since the network faced some problems in obtaining retro-active consents for the use of samples not included in previous studies from patients.
} 
focus mainly on transferring into clinical practice those LDTs that are quality controlled to assure the accuracy of the screening in the identification of the allele (Dello Russo et al, 2014).

The first HLA-B*57:01 External Quality Assurance (EQA) program carried out in Italy by the Network involved all the virology laboratories and ended in December 2014. The EQA program showed the proficiency of all the virology units in providing correct HLA-B*57:01 genotyping by inexpensive assays, mostly based on Q-PCR techniques (Meini et al., 2016). During the EQA one of the research teams reported the poor performance of a commercial test (Dello Russo et al, 2013). This occurrence was confirmed by another virology research centre on a larger sample using a similar technological platform (Falasca et al., 2016). Research on this aspect is still ongoing. Moreover, the network is currently studying the performance of a new commercial test which was not yet available on the market at the time ${ }^{12}$ against other methods already validated ${ }^{13}$. Preliminary results were presented at the Italian Conference on AIDS and Retroviruses (June, 2015).

Of course, before proceeding to the publication or presentation of the results, all findings are timely shared among network participants electronically and/or discussed at a network workshop.

State of play and prospective changes on the diffusion of the pharmacogenetic test in Italy

The diffusion of commercial tests and LDTs is closely monitored. Whilst data on the diffusion is not available, ViiV Healthcare Ltd monitors the diffusion of the procedure through its pharmaceutical representatives on the territory and reports that the test is now implemented across a large number of clinics in Italy. The host of qualitative information on 1) access to testing, 2) use of Abacavir containing therapies and 3) turnaround of the screening results confirm this upward trend. At the end of 2015, 67 large clinical centres distributed across the country prescribe HLA-B*57:01 testing referring patients and samples to over 50 virology/immune-genetic laboratories and a number of smaller clinical units routinely refer patients to larger diagnostic facilities. These would be the results directly attributable to what Homer (1987) refers as factors endogenous to clinical practice. However, these may also reflect the compound effect of exogenous factors. In fact, on the basis of the interviews and desk research we can conclude that the introduction of the pharmacogenetic test in the Italian Guidelines on the use of Antiretroviral Drugs and on the Clinical and Diagnostic Management of Patients affected by HIV-1 (December, 2014) contributed to the wider diffusion of the practice.

Nonetheless, there is still a 'cultural gap' at the point of service since physicians see the test as an added burden on their time notwithstanding the clear clinical benefits, its cost effectiveness and ease of interpretation of the results (HLA-B*57:01 positive or negative). Though, virology units in almost all Italian hospitals are 'kitted up' to perform the pharmacogenetic test which are routinely requested by the clinicians making the decision on the course of the treatment.

The research activity of the Network is continuing to investigate complementary issues including HRS independent from the presence of the HLA-B*57:01 allele in patients' DNA which has been highlighted by all, virologists and clinicians, as an area where there is not enough knowledge and further research is carried out accordingly.

\footnotetext{
${ }^{12}$ Duplica-RealTime HLA-B*5701 EZ Screen test (Euroclone).

${ }^{13}$ Duplica-Real Time Reagent Set HLA-B*57:01 (Euroclone).
} 
Moreover, the network commenced the activities for the development and validation of a novel streamlined method in Direct Q-PCR to simplify further the testing procedures. Direct PCR works directly with buccal swabs or blood samples, eliminating the need of DNA extraction (Cascella et al. 2015). This method consists in the translation of recent advances on a more basic technological platform - traditional PCR - enabling test facilities not endowed with the latest RealTime Q-PCR machine (i.e. in low-income countries) to perform the test.

Notwithstanding these excellent results, additional hurdles continue to emerge. Novel HIV/AIDS studies are demonstrating that the timing of the therapeutic impact has strong effects on the outcome of the disease bringing 'immediacy of intervention' at the top of the agenda (Lundgren et al 2015). Therefore, the turnaround time of the test result becomes highly discriminant in the prescription phase. This factor is also greatly amplified by the increasing occurrence of new cases of the disease diagnosed at an already advanced stage of viral infection and even with AIDS symptoms.

\section{Discussion and Conclusions}

This paper looks directly at the diffusion tail of the innovation process and builds evidence on the diffusion of medical innovation. Diffusion is just as important as science and development, and certainly as complex, although when analysed in the context of the innovation process it appears to be somewhat opaque. Specifically, our findings show that the production of scientific knowledge and the technological development process does not come to a halt once the diffusion phase begins. We pointed to new and overlapping problems pertaining to the domain of scientific research and technology development. These populated the problem matrix rather than extinguishing prior concerns, adding further complications during the diffusion of the therapy. Thus we noted a further layer of complexity needs to be added to the conceptualisations of the innovation process as a systemic phenomenon (Mina et al 2007; Metcalfe et al, 2005; Consoli et al, 2016). This challenges the prevailing paradigm within the pharmaceutical R\&D field and also the classical and mainstream literature on innovation diffusion (Rogers, 1995, Coleman et al, 1957) that the innovation process can be easily decoupled for analysis (Swen, 2007; Paul et al, 2010; Calcoen et al, 2015)

As observed in the case study, the wide diffusion of the pharmacogenetic test throughout Italy, and elsewhere, was the main objective of ViiV Healthcare. The science and the technology behind a potential broad diffusion of such tests seemed already sorted: drug-allele interaction for the prevention of the hypersensitivity reaction has been discovered since 2002 and validated soon after, and several diagnostic technologies to identify HLA-B*57:01 carriers became available within the Italian Health System and elsewhere in the early 2010s. Compared to the gold standard of sequencebased typing analysis, these diagnostic technologies offered a rapid turnaround of the results and could be performed in simple laboratory settings with an affordable price tag (Stocchi et al, 2012). However, a significantly broader diffusion of the test would require further effort in integrating it in the clinical practice to avoid the possibility that Abacavir might endanger patients and stall the diffusion of newer Abacavir-containing therapeutic solutions.

Whilst at first this might seem like a straight-forward case of diffusion of innovation, the pharmacogenetic screening in clinical practice involves the deployment of an additional test to be integrated with established diagnostic procedures. Thus, this case cannot be easily mapped onto the traditional theoretical infrastructure of innovation diffusion (Rogers, 1962; Coleman et al, 1957) or even newer approaches (Jerome-D’Emilia \& Begun, 2005; McKinlay \& Marceau, 2012; Liu \& Gupta, 2012; Shen \& Shih, 2016). It consists of an evolving case of diffusion of innovation in a complex 
environment. Here, practitioners and virology laboratories need to change their routines, learn of novel and evolving clinical guidelines and about new diagnostic techniques characterised by changing levels of uncertainty brought by ensuing advances in scientific enquiries and technological developments in the medical and diagnostic fields.

The changing context presented the pharmaceutical company with four main challenges. The first concerns encouraging the development and diffusion of a variety of techniques and diagnostic tests that may be used by clinicians and laboratories with different testing capabilities. Second, ensuring that the various testing processes are validated - that they actually work. Third, that the procedures during diagnosis and management of the treatment are standardised (or at least standardisable) and not tentative so that they could be used in a variety of clinical testing laboratories; and fourth, ensuring that testing can be available and integrated across all the sub-national health systems at a rapid turnaround.

The case of Abacavir and its companion diagnostic is considered a landmark case of translational medicine, in particular it is one of the first cases where the principles of pharmacogenetics, developed and tested at the benches of research organisations, in science/technology-based firms and medical research hospitals and clinics, have made an important - applied - contribution to medical innovation. Though, referring this case to the conceptual frameworks developed within the literature, we can see how it does not map perfectly either onto the traditional S-shaped diffusion framework or onto the co-diffusion of innovation proposed by Buckling and Sengupta (1993) and generally adopted because the technology is dynamic. Whilst Abacavir is increasingly used as 'ingredient' in new drugs, the testing techniques and procedures are beign researched, tested and certified. On the other hand, this case study fits rather poorly in the scant literature of diffusion of evolving technologies (Homer, 1987; Greer, 1988). The co-dependence between the diffusion of Abacavir/Abacavir-containing drugs and the pharmacogenetic test poses questions that the analysis of a single evolving technology may not be suited to asnwer. In other words, to appropriately undertake a study of the diffusion process, one has to think carefully about the unit of analysis (see below). Further, this case highlighted that the diffusion process is not discrete or easily decoupled from scientific and clinical research nor it is linearly connected to these activities and may also be affected by events and occurrences external to the problem space faced by stakeholders.

The case study analysed showed the diffusion process to have a multi-stakeholder base which is also affected by advances in science and technology originating from external sources whilst, at the same time, contributing to them. Admittedly, ViiV Healthcare took a leading role in translating the actual contributions into a workable solution in terms of organising the network and fostering the wider diffusion of the test across Italy. However scientific and technological trajectories were navigated by a range of contributors. In fact, the diffusion of the test, which at first occurred gradually, by 2015 began to gain momentum due to clinical centres prescribing the test and laboratories performing it. Moreover, apart from the intensive work carried out by the company and the Italian HLA-B*57:01 Network, the introduction of newer and revised guidelines in December 2014, highlighting the test as a necessary component of the clinical/diagnostic routine (Italian Ministry of Health, 2014; Table 1, p. 23) contributed significantly to its diffusion.

To this end, advocacy associations played an important active role in the promotion and dissemination of critical information on the role of the test in the therapeutic plans and in the subsequent phases thanks to their continual evaluation of factors, including costs, linked to the benefits/effectiveness of testing, its accessibility, and its clinical relevance. 
Nonetheless, scientific and clinical research is still ongoing within the network, the reasons being that i) some of the initial objectives have not been fully met ii) new ambitions have emerged in the course of the activities and iii) new unanticipated problems have materialised from multiple fronts for example, new research and clinical trials challenging the current technological arrangements and the logistics of operation, putting renewed pressure on turnaround times for test results.

Figure 4. conceptual framework for the analysis of co-diffusions of dynamic medical technologies

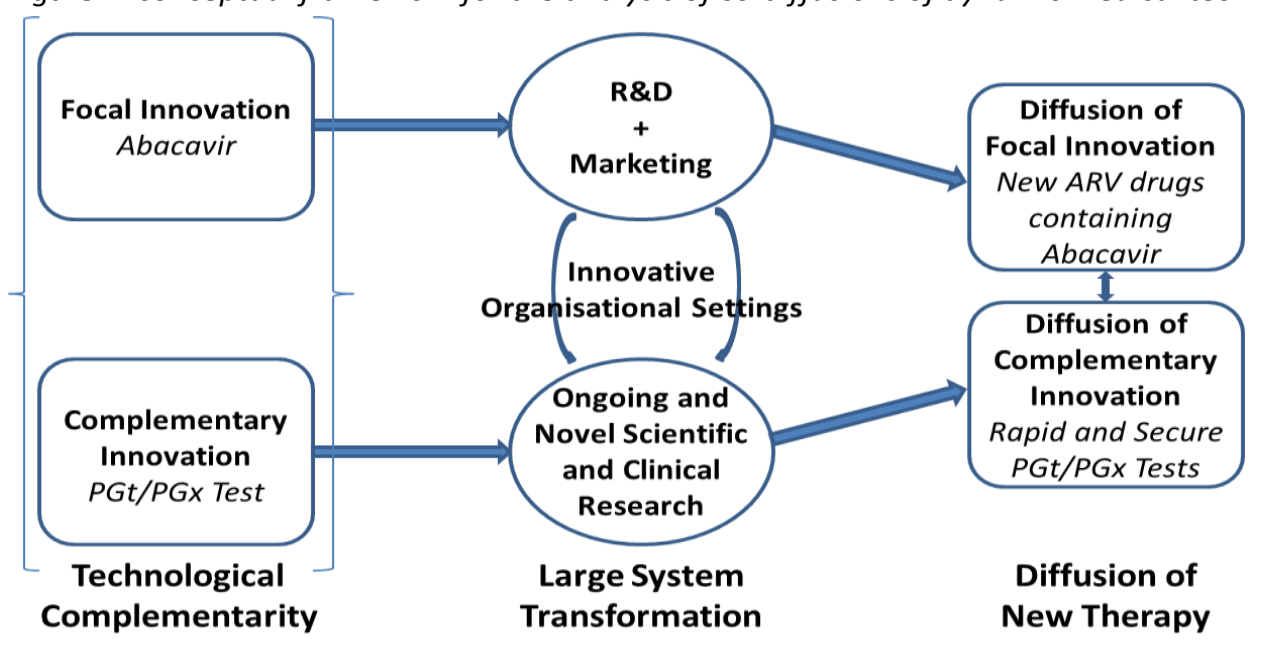

Source: own elaboration

All these 'ingredients' are all too often common in the diffusion process of a medical innovation. In fact, with an increasing rise in complementarities between drug products, diagnostics and interventions, the diffusion of a therapy takes centre stage relative to the diffusion of a single component (be it a drug, a device or a procedure). Here we would also like to emphasise the increasing interdependence between the manufacturing and the service economy highlighted by Metcalfe et al (2005, p.1301). In particular, how a drug-based therapy may become reliant on associated diagnostic services to the point that their diffusions become inextricable; therefore, to be meaningful, the object of analysis moves towards the therapy rather than its specific components.

Moreover, the provision of therapeutic services is based on the translation of basic research from complementary areas, the development of new/improved diagnostic technologies, and the creation and re-organisation of medical knowledge and clinical practices. This process, informing and transforming the therapy over time continually evolves and cannot be effectively studied as the diffusion of a single activity area since the diffusion phases are deep-seated within basic and clinical research and clinical practices. It is thus necessary to consider the systemic effects of the changes that occur during the translation of medical discoveries into clinical practice as these engender large systemic changes in clinical protocols and their application for the benefit of patients (figure 4).

Adopting this framework helps us to understand that the process of innovation is uneven and cumulative in nature, driven by multiple stakeholders/agencies. Rather than being envisaged as discrete and sequential activities, diffusion trajectories are the outcome of a series of overlapping and intertwined decisions and occurrences conditioned by basic and clinical research, clinical practice, institutional arrangements and user involvement. These decisions are mediated by the agency of the stakeholders and operate across the system-wide environment characterised by the scientific endeavour from many epistemic domains and specialist clinical competences. These work towards the discovery, refinement and application of new techniques within a system consisting of specific organisational routines operating within a given regulatory framework. 


\section{Acknowledgements}

The authors are indebted to Dr Antonella Pirazzoli of ViiV Healthcare Ltd., the managers and the members of the Italian HLA-B*57:01 Network for their support. The authors wish to thank also the members of the WOMI Community and in particular Andrea Mina who acted as our discussant at the Workshop On Medical Innovation held at CSIC-UVP in Valencia (ES), December 2015. Gratefully acknowledged is also the effort of Mickael Benaim for his critical reading of an earlier version of the manuscript and the contribution of two anonymous referees. Usual caveats apply.

Notes and disclosures: The authors did not receive any financial support for the present research. Pierluigi Navarra and Cinzia Dello Russo are part of the Italian HLA-B*57:01 Network.

\section{References}

Alagoz, O., Durham, D., \& Kasirajan, K. (2016). Cost-effectiveness of one-time genetic testing to minimize lifetime adverse drug reactions. The Pharmacogenomics Journal. 16, 129-136

Barberá-Tomás, D., \& Consoli, D. (2012). Whatever works: Uncertainty and technological hybrids in medical innovation. Technological Forecasting and Social Change, 79(5), 932-948.

Bass, F. M. (1969). A new product growth for model consumer durables. Management science, 15(5), 215-227.

Bass, F. M., Gordon, K., Ferguson, T. L., \& Githens, M. L. (2001). DIRECTV: Forecasting diffusion of a new technology prior to product launch. Interfaces, 31(3_supplement), S82-S93.

Best, A., Greenhalgh, T., Lewis, S., Saul, J. E., Carroll, S., \& Bitz, J. (2012). Large-system transformation in health care: a realist review. Milbank Quarterly, 90(3), 421-456.

Blume, S. S. (2013). Medical innovations: Their diffusion, adoption, and critical interrogation. Sociology Compass, 7(9), 726-737.

Bowen, G. A. (2009). Document analysis as a qualitative research method. Qualitative Research Journal, 9(2), 27-40.

Bucklin, L. P., \& Sengupta, S. (1993). The co-diffusion of complementary innovations: Supermarket scanners and UPC symbols. Journal of Product Innovation Management, 10(2), 148-160.

Burke, M. A., Fournier, G. M., \& Prasad, K. (2007). The diffusion of a medical innovation: is success in the stars?. Southern Economic Journal, 588-603.

Calcoen, D., Elias, L., \& Yu, X. (2015). What does it take to produce a breakthrough drug?. Nature Reviews Drug Discovery, 14(3), 161-162.

Cascella, R., Strafella, C., Ragazzo, M., Zampatti, S., Borgiani, P., Gambardella, S., ... \& Giardina, E. (2015). Direct PCR: a new pharmacogenetic approach for the inexpensive testing of HLA-B* 57: 01 . The pharmacogenomics journal 15, 196-200 
Cho, Y., Hwang, J., \& Lee, D. (2012). Identification of effective opinion leaders in the diffusion of technological innovation: A social network approach. Technological Forecasting and Social Change, 79(1), 97-106.

Coleman, J., Katz, E., \& Menzel, H. (1957). The diffusion of an innovation among physicians. Sociometry, 20(4), 253-270.

Consoli, D., \& Ramlogan, R. (2008). Out of sight: problem sequences and epistemic boundaries of medical know-how on glaucoma. Journal of Evolutionary Economics, 18(1), 31-56.

Consoli, D., Mina, A., Nelson, R. R., \& Ramlogan, R. (Eds.). (2016). Medical Innovation: Science, Technology and Practice. Routledge.

Dawson, S. (1995). Never mind solutions: what are the issues? Lessons of industrial technology transfer for quality in health care. Quality in Health Care,4(3), 197.

Dello Russo, C., Lisi, L., Lofaro, A., Di Giambenedetto, S., Federico, B., Madeddu, G., \& Navarra, P. (2011). Novel sensitive, specific and rapid pharmacogenomic test for the prediction of abacavir hypersensitivity reaction: HLA-B* 57: 01 detection by real-time PCR. Pharmacogenomics, 12(4), 567576.

Dello Russo, C., Lisi, L., Fabbiani, M., Cauda, R., \& Navarra, P. (2013). Detection of HLA-B*57:01 in real-time PCR: implementation into routine clinical practice, additional validation data and comparison with commercially available methods. New Microbiologica, 36, Suppl. 1: 193 (P122).

Dello Russo, C., Lisi, L., Fabbiani, M., Gagliardi, D., Fanti, I., Di Giambenedetto, S., ... \& Navarra, P. (2014). Detection of HLA-B* 57:01 by real-time PCR: implementation into routine clinical practice and additional validation data. Pharmacogenomics, 15(3), 319-327.

Falasca, F., Dello Russo, C., Mora, B., Pirazzoli, A., Fantauzzi, A., Navarra, P., ... \& Turriziani, O. (2016). Comparative Analysis of Real-Time Polymerase Chain Reaction Methods to Typing HLA-B* 57: 01 in HIV-1-Positive Patients.AIDS research and human retroviruses. 32(7), 654-657.

FDA (2017), Discussion Paper on Laboratory Developed Tests (LDTs) January 13, https://www.fda.gov/downloads/MedicalDevices/ProductsandMedicalProcedures/InVitroDiagnostic s/LaboratoryDevelopedTests/UCM536965.pdf [accessed 10th April, 2018]

Ferlie, E., Gabbay, J., Fitzgerald, L., Locock, L., \& Dopson, S. (2001). Evidence-based medicine and organisational change: an overview of some recent qualitative research. In, Ashburner, L. (eds.) Organisational behaviour and organisational studies in health care: Reflections on the future. Basingstoke, UK, Palgrave Macmillan, 18-42.

Ferreira, K. D., \& Lee, C. G. (2014). An integrated two-stage diffusion of innovation model with market segmented learning. Technological Forecasting and Social Change, 88, 189-201.

Flick, U. (2014). An introduction to qualitative research. $5^{\text {th }}$ Edition, Sage.

Golden, B. R. (1992). The past is the past-or is it? The use of retrospective accounts as indicators of past strategy. Academy of Management journal, 35(4), 848-860. 
Greenhalgh, T., Robert, G., Macfarlane, F., Bate, P., \& Kyriakidou, O. (2004). Diffusion of innovations in service organizations: systematic review and recommendations. Milbank Quarterly, 82(4), 581629.

Greenhalgh, T., Robert, G., Macfarlane, F., Bate, P., Kyriakidou, O., \& Peacock, R. (2005). Storylines of research in diffusion of innovation: a meta-narrative approach to systematic review. Social Science \& Medicine, 61(2), 417-430.

Greer, A. L. (1988). The state of the art versus the state of the science: the diffusion of new medical technologies into practice. International journal of technology assessment in health care, 4(01), 5-26.

Grol, R. (2001). Improving the quality of medical care: building bridges among professional pride, payer profit, and patient satisfaction. Jama, 286(20), 2578-2585.

Grol, R. P., Bosch, M. C., Hulscher, M. E., Eccles, M. P., \& Wensing, M. (2007). Planning and studying improvement in patient care: the use of theoretical perspectives. Milbank Quarterly, 85(1), 93-138.

Guseo, R., \& Guidolin, M. (2015). Heterogeneity in diffusion of innovations modelling: A few fundamental types. Technological Forecasting and Social Change, 90, 514-524.

Haines, A., \& Jones, R. (1994). Implementing findings of research. Bmj,308(6942), 1488-1492.

Harvey, W. S. (2011). Strategies for conducting elite interviews. Qualitative research, 11(4), 431-441.

Hetherington, S., Hughes, A.R., Mosteller, M., Shortino, D., Baker, K.L., Spreen, W., ... \& Roses, A.D. (2002). Genetic variations in HLA-B region and hypersensitivity reactions to abacavir. The Lancet, 359(9312), 1121-1122.

Homer, J. B. (1987). A diffusion model with application to evolving medical technologies. Technological Forecasting and Social Change, 31(3), 197-218.

Ilonen, J., Kamarainen, J. K., Puumalainen, K., Sundqvist, S., \& Kälviäinen, H. (2006). Toward automatic forecasts for diffusion of innovations. Technological Forecasting and Social Change, 73(2), 182-198.

Italian Ministry of Health (2014) Linee Guida Italiane sull'utilizzo dei farmaci antiretrovirali e sulla gestione diagnostico - clinica delle persone con infezione da HIV - 1, Guidelines of the Istituto superiore di Sanita' 18 December, 2014.

Kauf, T.L., Farkouh, R.A., Earnshaw, S.R., Watson, M.E., Maroudas, P., \& Chambers, M.G. (2010). Economic efficiency of genetic screening to inform the use of abacavir sulfate in the treatment of HIV. Pharmacoeconomics, 28(11), 1025-1039.

Jerome-D'Emilia, B., \& Begun, J. W. (2005). Diffusion of breast conserving surgery in medical communities. Social science \& medicine, 60(1), 143-151.

Liu, Q., \& Gupta, S. (2012). A Micro-level Diffusion Model for New Drug Adoption. Journal of Product Innovation Management, 29(3), 372-384.

Lundgren, J. D., Babiker, A. G., Gordin, F., Emery, S., Grund, B., Sharma, S., Avihingsanon, A., Cooper, D. A., ...\& Neaton, J. D. (2015) Initiation of Antiretroviral Therapy in Early Asymptomatic HIV Infection. N Engl J Med. 2015 Aug 27; 373(9), 795-807. 
Mallal, S., Nolan, D., Witt, C., Masel, G., Martin, A.M., Moore, C., ... \& Christiansen, F.T. (2002). Association between presence of HLA-B*5701, HLA-DR7, and HLA-DQ3 and hypersensitivity to HIV-1 reverse-transcriptase inhibitor abacavir. The Lancet, 359(9308), 727-732.

Mallal, S., Phillips, E., Carosi, G., Molina, J. M., Workman, C., Tomažič, J., ... \& Benbow, A. (2008). HLA-B*5701 screening for hypersensitivity to abacavir. New England Journal of Medicine, 358(6), 568-579.

Martin, M. A., \& Kroetz, D. L. (2013). Abacavir pharmacogenetics-from initial reports to standard of care. Pharmacotherapy: The Journal of Human Pharmacology and Drug Therapy, 33(7), 765-775.

Mclntyre, S. H. (1988). Market adaptation as a process in the product life cycle of radical innovations and high technology products. Journal of Product Innovation Management, 5(2), 140-149.

McKinlay, J. B. (1981). From" promising report" to" standard procedure": seven stages in the career of a medical innovation. The Milbank Memorial Fund quarterly. Health and society, 59(3), 374-411.

McKinlay, J. B., \& Marceau, L. D. (2012). From cottage industry to a dominant mode of primary care: stages in the diffusion of a health care innovation (retail clinics). Social science \& medicine, 75(6), 1134-1141.

Meini, G., Dello Russo, C., Allice, T., Barresi, R., D’Arrigo, R., Falasca, F., ... \& Baldanti, F. (2016). First external quality assurance program of the Italian HLA-B* 57: 01 Network assessing the performance of clinical virology laboratories in HLA-B* 57: 01 testing. Journal of Clinical Virology, 78, 1-3.

Metcalfe, J. S., James, A., \& Mina, A. (2005). Emergent innovation systems and the delivery of clinical services: The case of intra-ocular lenses. Research Policy, 34(9), 1283-1304.

Michalakelis, C., Varoutas, D., \& Sphicopoulos, T. (2010). Innovation diffusion with generation substitution effects. Technological Forecasting and Social Change, 77(4), 541-557.

Miller, C. C., Cardinal, L. B., \& Glick, W. H. (1997). Retrospective reports in organizational research: A reexamination of recent evidence. Academy of Management Journal, 40(1), 189-204.

Mina, A., Ramlogan, R., Tampubolon, G., \& Metcalfe, J. S. (2007). Mapping evolutionary trajectories: Applications to the growth and transformation of medical knowledge. Research policy, 36(5), 789806.

Mokyr, J. (1998). Induced technical innovation and medical history: an evolutionary approach. Journal of Evolutionary Economics, 8(2), 119-137.

Paul, S. M., Mytelka, D. S., Dunwiddie, C. T., Persinger, C. C., Munos, B. H., Lindborg, S. R., \& Schacht, A. L. (2010). How to improve R\&D productivity: the pharmaceutical industry's grand challenge. Nature reviews Drug discovery, 9(3), 203-214.

Pullen, A. J., Weerd-Nederhof, P. C., Groen, A. J., \& Fisscher, O. A. (2012). Open innovation in practice: goal complementarity and closed NPD networks to explain differences in innovation performance for SMEs in the medical devices sector. Journal of product innovation management, 29(6), 917-934.

Rogers, E. M. (1962). Diffusion of innovations, New York: Free Press. 
Rogers E. M. (1995). Diffusion of innovations. $4^{\text {th }}$ edition, New York: Free Press

Semitiel-Garcia, M., \& Noguera-Mendez, P. (2012). The structure of inter-industry systems and the diffusion of innovations: The case of Spain. Technological Forecasting and Social Change, 79(8), 1548-1567.

Shen, C., \& Shih, Y. C. T. (2016). Therapeutic Substitutions in the Midst of New Technology Diffusion: the Case of Treatment for Localized Prostate Cancer. Social Science \& Medicine.

Skinner, J., \& Staiger, D. (2005). Technology adoption from hybrid corn to beta blockers (No. w11251). National Bureau of Economic Research.

Stocchi, L., Cascella, R., Zampatti, S., Pirazzoli, A., Novelli, G., \& Giardina, E. (2012). The pharmacogenomic HLA biomarker associated to adverse abacavir reactions: comparative analysis of different genotyping methods. Current Genomics, 13(4), 314-320.

Svicher, V., D'Arrigo, R., Alteri, C., Andreoni, M., Angarano, G., Antinori, A., ... \& Borderi, M. (2010). Performance of genotypic tropism testing in clinical practice using the enhanced sensitivity version of Trofile as reference assay: results from the OSCAR Study Group. The new microbiologica, 33(3), 195-206.

Svicher, V., Alteri, C., Artese, A., Zhang, J. M., Costa, G., Mercurio, F., D'Arrigo, R., Alcaro, S., Palù, G., ...\& Perno, C.F.; OSCAR study group. Identification and structural characterization of novel genetic elements in the HIV-1 V3 loop regulating coreceptor usage. Antivir Ther. 2011;16(7):1035-45

Swen, J. J., Huizinga, T. W., Gelderblom, H., de Vries, E. G., Assendelft, W. J., Kirchheiner, J., \& Guchelaar, H. J. (2007). Translating pharmacogenomics: challenges on the road to the clinic. PLoS Med, 4(8), e209.

Talke, K., \& Hultink, E. J. (2010). Managing diffusion barriers when launching new products. Journal of Product Innovation Management, 27(4), 537-553.

Tutton, R. (2012). Personalizing medicine: futures present and past. Social Science \& Medicine, 75(10), 1721-1728.

Van Norman, G. A. (2016). Drugs and devices: comparison of European and US approval processes. JACC: Basic to Translational Science, 1(5), 399-412.

Wolf, E., Blankenburg, M., Bogner, J. R., Becker, W., Gorriahn, D., Mueller, M. C., ... \& Stoll, M. (2010). Cost impact of prospective HLA-B* 5701-screening prior to abacavir/lamivudine fixed dose combination use in Germany. European Journal of Medical Research, 15(4), 145-151.

Yin, R. K. (2013). Case study research: Design and methods. $5^{\text {th }}$ Edition, Sage publications.

Yücel, G., \& van Daalen, C. E. (2011). Exploratory analysis of the impact of information dynamics on innovation diffusion. Technological Forecasting and Social Change, 78(2), 358-372. 